\title{
A minor wound with a fatal course
}

\author{
Christoph Loeffler, ${ }^{1}$ Georg Mols, ${ }^{2}$ Kai Hecksteden, ${ }^{3}$ Jens Pfeiffer, ${ }^{1}$ Gerd J Ridder ${ }^{1}$ \\ ${ }^{1}$ Department of Otorhinolaryngology - Head and Neck Surgery, University of Freiburg, Freiburg, Germany; \\ 2Department of Anaesthesia, Hirslanden Klinik, Zuerich, Switzerland; \\ ${ }^{3}$ HNO Praxis Loerrach, Loerrach, Germany
}

Correspondence to Dr Christoph Loeffler, christoph.loeffler@uniklinik-freiburg.de

\section{Summary}

The authors report on a fatal case of severe tetanus in a 74-year old woman. Despite comprehensive intensive care management they could not achieve a satisfying control of the autonomic dysfunction caused by tetanus. By now there is no established therapy for the treatment of the autonomic dysfunction. This report demonstrates the dismal prognosis of severe tetanus in the older people, which is often complicated by cardiovascular comorbidity and underlines the importance of tetanus prevention by sufficient vaccination.

\section{BACKGROUND}

Tetanus is nowadays a rare disease in developed countries, but mortality still remains high. Patients aged over 60 years are at greatest risk for tetanus infection. This increased risk results from inadequate immunity due to the vaccination status with advanced age: some of these patients might never have been vaccinated at all while others missed their vaccination boosters. Subsequently, a considerable part of the older people does not have a protective antibody level against tetanus. ${ }^{1}$ The increased presence of cardiovascular diseases in the older people complicates the treatment of the autonomic dysfunction, which has become the main cause of death since respiratory failure can be prevented by mechanical ventilation.

Because of its poor outcome, the prevention of tetanus by sufficient vaccination is without choice.

As the disease and its vaccination are frequently forgotten, we think it is important to present our experience to a large number of physicians.

\section{CASE PRESENTATION}

A 78-year-old woman presented at our ENT outpatient department with an increasing lockjaw since the previous day. She was known to suffer from a renal insufficiency that required chronic dialysis, from paroxysmal atrial fibrillation as well as from a pre-existing coronary artery disease. Initially, the patient was clinically stable and fully responsive.

A prior tetanus vaccination was not memorable to the patient.

\section{INVESTIGATIONS}

Fiberoptic pharyngo-laryngoscopy indicated no signs of injuries or an inflammation in the upper airways. Particularly noticeable was an increase of the tonus of the masseter muscle as the cause of the lockjaw but also a mild generalised muscle rigidity. On inquiry, the patient reported about an injury of the left lower leg sustained while gardening 1 week before. The skin lesion presented reddened with a seropurulent exudate (figure 1).

\section{DIFFERENTIAL DIAGNOSIS}

Laboratory investigations are not revealing except for negative findings, so the diagnosis of tetanus has to be made based on the typical clinical findings with increased muscle tone of the head and neck region due to spasms. Strychnine poisoning is the only differential diagnosis because it may mimic the initial clinical picture of tetanus, but not the autonomic dysfunction.

Tetanus is unlikely if a vaccination has been completed previously and protective serum antitoxin levels are found. Nevertheless there are case reports of tetanus in immune competent individuals with 'protective' antibody levels. ${ }^{2} 3$ The isolation of Clostridium tetani from the patient's wound is unreliable and typically not positive. ${ }^{4}$

\section{TREATMENT}

Within hours, the patient developed respiratory failure requiring emergent nasotracheal intubation. Furthermore, as a sign of autonomic dysfunction, the patient showed a fluctuating blood pressure and tachycardia that could barely be controlled by sophisticated medication based on invasive monitoring of circulation. We performed a prompt wound debridement and administered tetanus antitoxin subcutaneously. Further on, a high-dose antibiotic therapy with metronidazole was initiated. To control persistent generalised spasms, benzodiazepines and propofol were given. Magnesium was given intravenously for the additional control of spasms and cardiovascular stabilisation. Initially, these measures were sufficient. However, during the further course of the disease, severe cardiovascular instability and recurrent spasms occurred. The latter required intermittent application of muscle relaxants. 


\section{BMJ Case Reports}

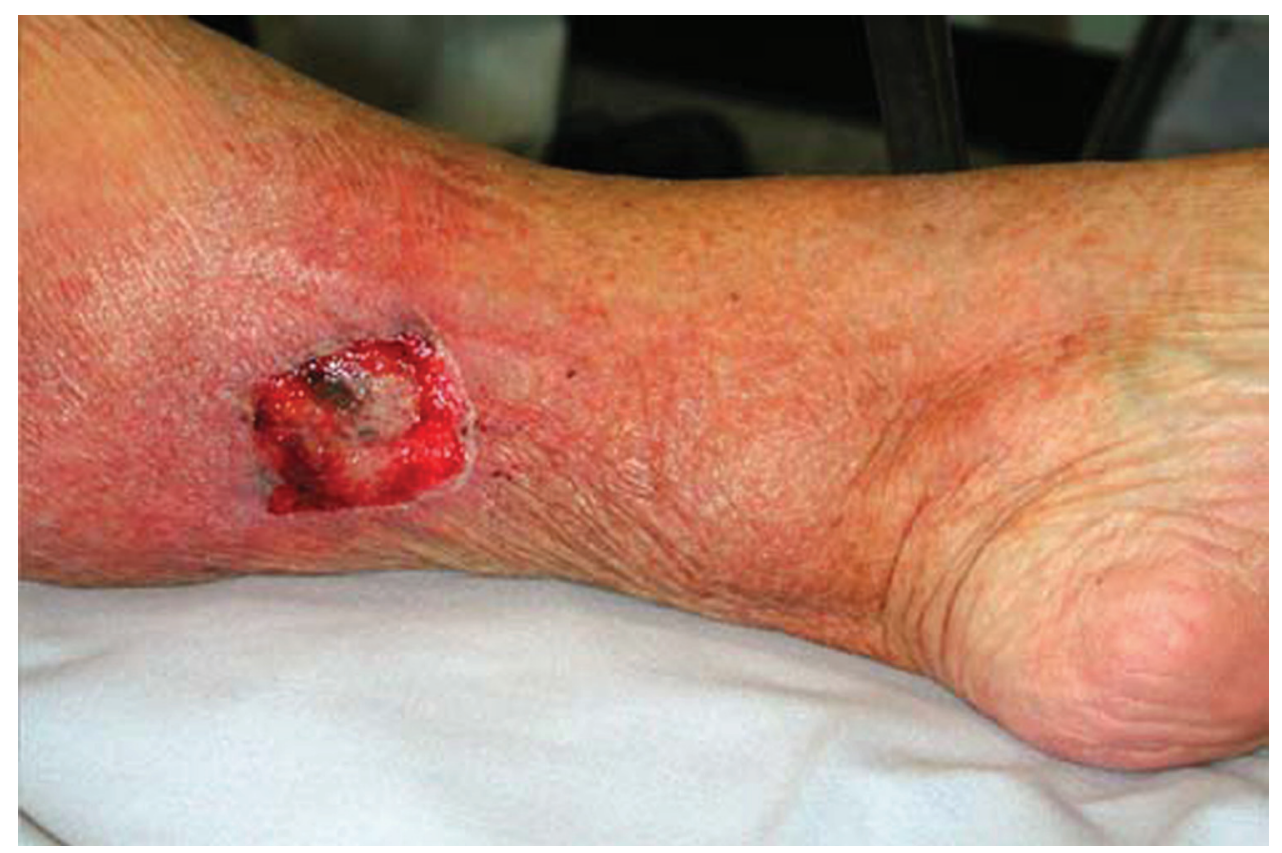

Figure 1 An injury of the left lower leg sustained while gardening was the portal of entry for the generalised tetanus infection.

\section{OUTCOME AND FOLLOW-UP}

With repeated episodes of profound hypotension, the patient deceased on the 28th day of treatment on cardiac failure. Serological findings confirmed a missing immunity against tetanus.

\section{DISCUSSION}

The treatment aims at the binding of circulating toxin, prevention of further toxin production, and minimising its effects on the central and peripheral nervous system. Toxin already bound to the central nervous system cannot be neutralised by antitoxin.

\section{Antitoxin}

Human tetanus immunoglobulin of 500-6000 units should be applied immediately. The optimal dosage and duration of antitoxin therapy is not known, recommendations are inconsistent in literature. ${ }^{5} 6$

\section{Prevention of toxin production}

Wounds as being the entry side for $C$ tetani should be explored, debrided and thoroughly cleaned. ${ }^{1}$ Antibiotic therapy improves survival rate and reduces the need for muscle relaxants. ${ }^{7}$ Penicillin as a $\gamma$-aminobutyric acid (GABA) antagonist may counteract the therapy with benzodiazepines so metronidazole seems to be the antibiotic of choice. Clindamycin, tetracyclin and erythromycin are acceptable alternatives. ${ }^{1}$

\section{Minimising the toxin effect}

The patient should be taken to an intensive care unit. Early intubation and mechanical ventilation is necessary to minimise the risk of pulmonary complications. ${ }^{1}$ Some authors favour early elective tracheotomy as laryngeal spasms or aspiration may occur unexpectedly at any time even in mild forms of the disease. ${ }^{8}$
To control the spasms and muscle rigidity benzodiazepines are the standard therapy. Also, the patient should be protected from unnecessary stimulation. If adequate sedation could not be achieved by this regimen, propofol and neuromuscular blocking agents (particularly vecuronium with low side effects on the cardiovascular system) can be administered. ${ }^{1}$

The use of intrathecal baclofen, a GABA antagonist, that does not penetrate the blood-brain barrier, has been described in case series. ${ }^{5} 9$ Because of high invasiveness, varying outcome und induction of deep coma, Baclofen cannot be recommended as a standard therapy of tetanus. ${ }^{1}$

\section{Autonomic dysfunction}

Since mechanical ventilation and effective control of muscle spasms avoid respiratory failure, cardiac arrest due to the autonomic dysfunction has become the main cause of death. ${ }^{10}$ Most authors attribute the autonomic dysfunction to an overactivity of the sympathetic nervous system with elevated serum catecholamine level. ${ }^{11}$

Treatment of the autonomic dysfunction remains challenging. Although a variety of case reports with different treatment strategies can be found, improvement of mortality is often inconsistent.

Sedation is the primary therapy to reduce sympathetic activity. Benzodiazepines are useful for sedation and muscle relaxation, but have little effect on sympathetic activity. ${ }^{12}$ Morphines lower the sympathetic overactivity and stabilise the cardiovascular status. ${ }^{12}$

Epidural blockades with local anaesthetics are reported to lower the sympathetic tonus and stabilise the cardiovascular situation. ${ }^{13} 14$ As continuous infusion may be required the possibility of infectious complications at the catheter site limits the use of epidural blockade. ${ }^{14}$

Several studies describe the use of adrenergic blockade to attenuate the effect of the elevated catecholamine levels. 
While some authors describe adequate control of tachycardia and hypertension with an $\alpha / \beta$-adrenergic blockade ${ }^{15}$ several authors associate these agents with acute cardiac failure when sympathetic tonus reverses. ${ }^{1}$ Edmondson and Flowers report on sudden bradycardia and cardiac arrest of two young and previously fit patients during tracheal suction. ${ }^{16}$ These agents cannot be recommended as a standard therapy of autonomic dysfunction because of dangerous unpredictable effects when sympathetic activity suddenly declines.

Clonidine lowers sympathetic activity by stimulating $\alpha_{2}$-adrenergic receptors in the brain stem. ${ }^{11}$ It also inhibits catecholamine release from the adrenal medulla and norepinephrine release from peripheral prejunctional endings. ${ }^{1}$ After the administration of clonidine Sutton et al found a decrease in plasma norepinephrine associated with a reduction of cardiovascular instability in a patient with severe tetanus. ${ }^{11}$ Gregorakos et al even demonstrated in a small randomised study a decrease in mortality in cardiovascular instable patients treated with clonidine compared to patients, who did not receive clonidine. ${ }^{17}$ In contrast two case reports describe the failure of clonidine to control blood pressure and lower catecholamine excesses. ${ }^{18} 19$

Several studies recommend the administration of magnesium sulphate to attenuate catecholamine levels and receptor responsiveness. In vitro studies show a reduction of catecholamine release from both the adrenal medulla and peripheral nerve endings. ${ }^{1}$ In patients with pheochromocytoma, magnesium sulphate reduces the release of epinephrine, ${ }^{20}$ so magnesium sulphate seems an interesting option for reducing the autonomic dysfunction in severe Tetanus caused by elevated catecholamine levels. In a placebo controlled study with 195 patients in total, Thwaites et al showed a significant reduction of the requirement of drugs to control muscle spasms and cardiovascular stability in patients with magnesium infusions but no difference in survival and requirement for mechanical ventilation. ${ }^{21}$ James and Manson described an improvement of haemodynamic parameters during infusion of magnesium in 9 subjects with persistent autonomic dysfunction despite heavy sedation. ${ }^{22}$ Lipman used magnesium sulphate in a case report during a sympathetic crisis. He achieved a stabilisation of cardiovascular function as well as a decrease in catecholamine levels, but also found that magnesium without other sedatives was not effective. ${ }^{23}$

However, in our case we could not achieve a satisfying control of the sympathetic overactivity by magnesium sulphate.

Due to the progressive heart failure with episodes of severe hypotension, we did not use clonidine.

This case demonstrates the dismal prognosis of severe tetanus in the older people. Cardiovascular comorbidity complicates the treatment of sympathetic overactivity. In our case, the patient developed a fatal cardiac deterioration that could not be prevented with comprehensive intensive care management.

Because tetanus still has a poor outcome, its prevention by sufficient vaccination is mandatory.

\section{Learning points}

- Tetanus is a clinical diagnosis, because laboratory findings are non-contributory except for negative findings.

- Today mechanical ventilation and improved control of muscle spasms avoid respiratory failure, so cardiac arrest due to a concomitant autonomic dysfunction has become the main cause of death in tetanus.

- Insufficient seroprotection is common among the older people in industrial countries.

- The prevention of tetanus by sufficient vaccination is mandatory since Tetanus has a dismal prognosis among the older people.

\section{Competing interests None}

Patient consent Obtained.

\section{REFERENCES}

1. Cook TM, Protheroe RT, Handel JM. Tetanus: a review of the literature. $\mathrm{Br} \mathrm{J}$ Anaesth 2001;87:477-87

2. Crone NE, Reder AT. Severe tetanus in immunized patients with high antitetanus titers. Neurology 1992:42:761-4.

3. Passen EL, Andersen BR. Clinical tetanus despite a protective level of toxinneutralizing antibody. JAMA 1986;255:1171-3.

4. Murphy TV, Slade BA, Broder KR, et al. Prevention of pertussis, tetanus, and diphtheria among pregnant and postpartum women and their infants recommendations of the Advisory Committee on Immunization Practices (ACIP). MMWR Recomm Rep 2008; 57(RR-4):1-51.

5. Attygalle D, Rodrigo N. New trends in the management of tetanus. Expert Rev Anti Infect Ther 2004;2:73-84.

6. Abrutyn E. Tetanus. In: Kasper DL, Braunwald E, Fauci AS, Hauser SL, Longo $\mathrm{DL}$, Jameson JL, eds. Harrison's Principles of Internal Medicine. 16th edition. New York, NY: McGraw-Hill 2004:840-2.

7. Bunch TJ, Thalji MK, Pellikka PA, et al. Respiratory failure in tetanus: case report and review of a 25-year experience. Chest 2002;122:1488-92.

8. Aydin K, Caylan R, Caylan R, et al. Otolaryngologic aspects of tetanus. Eur Arch Otorhinolaryngol 2003;260:52-6.

9. Santos ML, Mota-Miranda A, Alves-Pereira A, et al. Intrathecal baclofen for the treatment of tetanus. Clin Infect Dis 2004;38:321-8.

10. Trujillo MH, Castillo A, España J, et al. Impact of intensive care management on the prognosis of tetanus. Analysis of 641 cases. Chest 1987;92:63-5.

11. Sutton DN, Tremlett MR, Woodcock TE, et al. Management of autonomic dysfunction in severe tetanus: the use of magnesium sulphate and clonidine. Intensive Care Med 1990;16:75-80.

12. Buchanan N, Cane RD, Wolfson G, et al. Autonomic dysfunction in tetanus: the effects of a variety of therapeutic agents, with special refernce to morphine. Intensive Care Med 1979;5:65-8.

13. Southorn PA, Blaise GA. Treatment of tetanus-induced autonomic nervous system dysfunction with continuous epidural blockade. Crit Care Med 1986;14:251-2

14. Bhagwanjee $\mathbf{S}$, Bösenberg AT, Muckart DJ. Management of sympathetic overactivity in tetanus with epidural bupivacaine and sufentanil: experience with 11 patients. Crit Care Med 1999;27:1721-5.

15. Kanarek DJ, Kaufman B, Zwi S. Severe sympathetic hyperactivity associated with tetanus. Arch Intern Med 1973;132:602-4.

16. Edmondson RS, Flowers MW. Intensive care in tetanus: management complications, and mortality in 100 cases. Br Med J 1979;1:1401-4.

17. Gregorakos L, Kerezoudi E, Dimopoulos G, et al. Management of blood pressure instability in severe tetanus: the use of clonidine. Intensive Care Med 1997;23:893-5.

18. Brown JL, Sinding H, Mathias CJ. Autonomic disturbance in severe tetanus: failure of parenteral clonidine to control blood pressure. $J$ Infect 1994;29:67-71. 


\section{BMJ Case Reports}

19. Freshwater-Turner D, Udy A, Lipman J, et al. Autonomic dysfunction in tetanus - what lessons can be learnt with specific reference to alpha-2 agonists? Anaesthesia 2007;62:1066-70.

20. James MF. Use of magnesium sulphate in the anaesthetic management of phaeochromocytoma: a review of 17 anaesthetics. Br J Anaesth 1989;62:616-23.
21. Thwaites CL, Yen LM, Loan HT, et al. Magnesium sulphate for treatment of severe tetanus: a randomised controlled trial. Lancet 2006;368:1436-43.

22. James MF, Manson ED. The use of magnesium sulphate infusions in the management of very severe tetanus. Intensive Care Med 1985;11:5-12.

23. Lipman J, James MF, Erskine J, et al. Autonomic dysfunction in severe tetanus: magnesium sulfate as an adjunct to deep sedation. Crit Care Med 1987:15:987-8.

This pdf has been created automatically from the final edited text and images.

Copyright 2011 BMJ Publishing Group. All rights reserved. For permission to reuse any of this content visit http://group.bmj.com/group/rights-licensing/permissions.

BMJ Case Report Fellows may re-use this article for personal use and teaching without any further permission.

Please cite this article as follows (you will need to access the article online to obtain the date of publication).

Loeffler C, Mols G, Hecksteden K, Pfeiffer J, Ridder GJ. A minor wound with a fatal course. BMJ Case Reports 2011;10.1136/bcr.04.2011.4100, date of publication

Become a Fellow of BMJ Case Reports today and you can:

- Submit as many cases as you like

- Enjoy fast sympathetic peer review and rapid publication of accepted articles

- Access all the published articles

- Re-use any of the published material for personal use and teaching without further permission

For information on Institutional Fellowships contact consortiasales@bmjgroup.com

Visit casereports.bmj.com for more articles like this and to become a Fellow 